\title{
Extensive Involvement of Multiple Cranial and Spinal Nerves in Lymphomatous Meningitis - ERRATUM
}

\author{
Christian Cordano, Bardia Nourbakhsh, Ethan Brown, Christine Glastonbury
}

doi:https://doi.org/10.1017/cjn.2017.50, Published by Cambridge University Press, 09 May 2017

"Extensive Involvement of Multiple Cranial and Spinal Nerves in Lymphomatous Meningitis" by Cordano, Nourbakhsh, Brown \& Glastonbury published with an error in the statement of co-authorship, stating that " $\mathrm{CG}$ and $\mathrm{BN}$ contributed equally to the manuscript."

The corrected statement should read:

"*CC and BN contributed equally to the manuscript".
Additionally, the authors' names "Christian Cordano" and "Bardia Nourbakhsh" should appear with asterisks.

The original article has been corrected online to rectify this error.

\section{REFERENCE}

1. Cordano C, Nourbakhsh B, Brown E, Glastonbury C. (2017). Extensive Involvement of Multiple Cranial and Spinal Nerves in Lymphomatous Meningitis. Canadian Journal of Neurological Sciences/Journal Canadien Des Sciences Neurologiques. Published online: 09 May 2017. doi: 10.1017/cjn.2017.50. 